\title{
Emotional Empathy, Social Distance and Attitude of Police Officers towards People with Mental Illness
}

\author{
Olusola I. Akinbobola* (1), Sheba Y. Zugwai \\ Department of Behavioural Studies, Redeemer's University, Ede, Osun State, Nigeria \\ Email: *solaakinbobola@yahoo.co.uk
}

How to cite this paper: Akinbobola, O. I., \& Zugwai, S. Y. (2019). Emotional Empathy, Social Distance and Attitude of Police Officers towards People with Mental Illness. Psychology, 10, 830-843.

https://doi.org/10.4236/psych.2019.106054

Received: March 20, 2019

Accepted: May 12, 2019

Published: May 15, 2019

Copyright (๑) 2019 by author(s) and Scientific Research Publishing Inc. This work is licensed under the Creative Commons Attribution International License (CC BY 4.0).

http://creativecommons.org/licenses/by/4.0/

\section{(c) (i) Open Access}

\begin{abstract}
People with mental illness are generally stigmatized. This study therefore specifically investigated the relationship between emotional empathy, social distance and attitude towards mental illness by police officers who interface with people with mental illness in the course of duty. A total of 300 police officers comprising of 148 (49.3\%) males and 152 (50.7\%) females were selected from the Police Training College Ikeja, Lagos State. This study adopted a cross sectional survey using purposive sampling technique. The instruments for data collection were structured psychological scales which are the multi-dimensional emotional empathy scale, social distance scale and community attitude toward mental illness scale. Data collected were analysed using multiple regression and independent $t$ test. The result indicated that emotional empathy and its dimensions (suffering, positive sharing, responsive crying, emotional attention, feel for others, emotional contagion) and social distance had significant joint influence on attitude towards people with mental illness $[\mathrm{F}(7,292)=2.85, P<.01)]$. However, emotional empathy $(\beta=.58, \mathrm{t}=2.46, \mathrm{P}$ $<0.01)$, positive sharing $(\beta=-.52, \mathrm{t}=-3.84, P<0.01)$ and responsive crying $(\beta=-.15, \mathrm{t}=-2.06, P<0.05)$ had significant independent influence on attitude towards people with mental illness. Also, male police officers exhibit more sympathetic attitude towards people with mental illness than female police officers $\{\mathrm{t}(298)=-1.778, P<0.05\}$. Recommendation is made for psychological intervention to police officers for zero stigmatisation tolerance, and training on emphatic altruism and concern.
\end{abstract}

\section{Keywords}

Emotional Empathy, Social Distance, Attitude towards the Mentally Ill, Stigmatisation, Police Officers 


\section{Introduction}

Attitude is a favourable or unfavourable (Albarracin \& Shavitt, 2018) evaluative response toward something or someone, exhibited in one's beliefs, feelings, or intended behaviour (Eagly \& Chaiken, 2005). Attitude covers cognition, affection and action about something or people such as people with mental illness. Mental illness is a mental pattern that causes significant impairment of personal functioning (Bolton, 2008) which could range from mild to severe disturbances in thought and/or behavior, resulting in an inability to cope with life's ordinary demands and routines. People with mental illness are viewed by the public as subject of pity living in their disconnected, bizarre worlds (Todor, 2013).

\section{Literature Review}

Invariably, the public are often misinformed about mental illness. These misunderstandings of the public about mental illness tend to lead to stigmatisation of people with mental illness (Poreddi, Thimmaiah, \& Math, 2015). Stigma is stereotypic, mark of shame and disapproval which results in an individual being rejected and excluded from participating in a number of different areas of society (Yap, Mackinnon, Reavley, \& Jorm, 2014). Rusch, Angermeyer and Corrigan (2005) posit a model that stigmatisation occurs based on information that people with mental illness tend to be dangerous therefore should be kept at distant; people with mental illness are irresponsible, thus crucial decisions should be made by others on their behalf; and lastly, people with mental illness are childlike, therefore need to be cared for. These information available to public could have consequences for people with mental illness.

Stigmatisation can manifest as self stigma and as public stigma. Self-stigmatisation may lead to withdrawal by people with mental illness to their shell. Subsequently, people with mental illness may suffer self stigma and experience strong emotional response such as fear and rejection (Marie \& Miles, 2008; Sarbin \& Mancuso, 1970; Yuan, Abdin, Picco, Vaingankar, Shahwan, Jeyagurunathan, \& Subramaniam, 2016) which include low levels of empowerment, and low levels of help-seeking behaviour, high rates of mortality and high rates of unemployment (Bhugra, Evans-Lacke, \& Cutter, 2015). Stigmatisation makes people with mental illness delay or refuse to seek out help which result in worsen mental health experiences. This in turn may result in isolation, hopelessness, and low self-esteem (McAllister, 2008).

Again, Link, Cullen, Struening, Patrick, Shrout, and Dohrenwend (1989) modified labelling theory purported that people with mental illness are treated separately by the public. The labelled people with mental illness perceive threat and in turn may react to labelling by adopting strategies of either educating others of their situation, or keeping mental illness a secret or avoiding social interactions that they find potentially rejecting (Glass, Mowbray, Link, Kristjansson, \& Bucholz, 2013). These strategies have negative consequences on the well-being of people with mental illness. 
Also, public stigmatisation can lead to the other members of the public keeping social distance from the people with mental illness. The members of the public who stigmatise have the tendency to socially distant themselves from people with mental illness (Corrigan, Green, Lundin, Kubiak, \& Penn, 2001). Social distance is the degree of proximity the public is comfortable with in relation to people with mental illness; the extent to which the public is willing to get to with people with mental illness. According to (Marie \& Miles, 2008) perceived dangerousness and unpredictability of a target such as people with mental illness influence social distance. Social distance may manifest itself in such stigmatising experiences for people with mental illness that makes them have limited access to resources and get in the way of socialising with the public.

Conversely, an individual may help others in need out of empathic concern for the well-being of the other person (Batson, Dyck, Brandt, Batson, \& Powell, 1988; Batson \& Toi, 1982). The individual is emphatic and has the ability to comprehend the affective and cognitive status of another. Empathy is an individual's emotional arousal elicited by the expression of distress in another (Shelton \& Rogers, 1981). By paying attention to the cognitive status of others than one's experiences (Toussaint \& Webb, 2005). Being more concern with cognitive perception and cognitive identification (Eisenberg \& Lennon, 1983) of the others' experiences (Toussaint \& Webb, 2005) and having the ability to reverse the understanding and intent to assist (Hojat, Louis, Maio, \& Gonnella, 2013; Jonason \& Krause, 2013) for instance people with mental illness.

Previous studies have pointed out the importance of empathy in improving attitudes toward stigmatized groups. Feeling empathy for a member of a stigmatised group or the stigmatised group as a whole can improve attitude, reduce or change negative attitude toward the stigmatized group (Batson, Polycarpou, Harmon-Jones, Imhoff, Mitchener, Bednar, Klein, \& Highberger, 1997; Oliver, Dillard, Bae, \& Tamul, 2012). Individuals who are more empathetic tend to have more positive attitude towards members of a stigmatized group (Boag \& Carnelley, 2015) and towards people with mental illness (Batson, Polycarpou, Harmon-Jones, Imhoff, Mitchener, Bednar, Klein, \& Highberger, 1997; Elizur \& Rosenheim, 1982). Studies have shown that the inability of the public to fully understand mental illness leads to negative attitude towards people suffering from mental illness (Nordt, Rössler, \& Lauber, 2006; Yuan, Abdin, Picco, Vaingankar, Shahwan, Jeyagurunathan, \& Subramaniam, 2016).

Research on social distance and attitude towards people with mental illness by Todor (2013) indicated that students in tertiary institutions lack the willingness to communicate with persons who have mental illness and furthermore that not having past contact with people mentally illness has significant relationship with larger social distance. However, with lowered social distance, the attitude of medical students toward schizophrenia was improved through antistigma intervention programmes (Altindag, Yanik, Ucok, Alptekin, \& Ozkan, 2006). Oduguwa, Adedokun, Omigbogun (2017) found that contact strategy reduce stigma and social distance. Whereas the opportunities such as accommodating, employment; if given to 
people with mental illness (Corrigan, Green, Lundin, Kubiak, \& Penn, 2001), will reduce negative attitude of the public.

Research on sex and attitude towards people with mental illness has shown that women are better at understanding emotions and thoughts of other individuals than men (Baez, Flichtentrei, Prats, Mastandueno, García, Cetkovich, \& Ibáñez, 2017). Researchers, Gonzalez, Alegria and Prihoda (2005), Berger, Levant, McMillan, Kelleher and Sellers (2005) found that men tend to show a more negative attitude towards mental illness indicating that women have a better attitude towards mental illness than men.

Police officers in the course of duty come in contact with people suffering from mental illness. The fundamental duties of a police officer as law enforcement officers include serving the community, safeguarding lives and property, protecting the innocent, maintaining order and peace, detection of crime, arresting and detaining suspect (Interpol, 2016). Aside from health professionals, no other group is tasked to manage and interact with people with mental illness more than police officers (Tully \& Smith, 2015). Therefore, people with mental illness are more likely to be arrested, incarcerated or killed by police officers than other members of the public.

Attitudes toward people with mental illness are important to study for a number of reasons. There is high prevalence of mental illness estimated at about twenty-five percent of the population in many countries (Todor, 2013) in general, while about 21 million Nigerians suffer from mental illness (Sotubo, 2015; Ifijeh, 2015). There is also high prevalence of negative attitudes among the general public toward people with mental illness. It is commonly held that people who suffer from any form of mental illness cannot be predicted and are perceived as dangerous. As a result of these people with mental illness may likely suffer negative attitudes from law enforcement officers such as the police, they are erroneously perceived as suspects, criminals (Omori, Tateno, Ideno, Takahashi, Kawashima, Takemura, \& Okubo, 2012).

Previous researchers studied attitude towards people with mental illness among clergy (Igbinomwanhia, James, \& Omoaregba, 2013); medical students (Altindag, Yanik, Ucok, Alptekin, \& Ozkan, 2006; Elizur \& Rosenheim, 1982); Poreddi, Thimmaiah, \& Math, 2015; secondary school students (Adeosun, Fatiregun, \& Suraju Adeyemo, 2017; Dogra, Omigbodun, Adedokun, Bella, Ronzoni, \& Adesokan, 2012); intensive care nurses (Gosselin, Bourgault, \& Lavoie, 2016); undergraduates (Shruti, Singh, \& Kataria, 2016); general public (Yuan, Abdin, Picco, Vaingankar, Shahwan, Jeyagurunathan, \& Subramaniam, 2016); psychiatrict/psychiatric nurses (Sun, Fan, Nie, Zhang, Huang, He, \& Rosenheck, 2014).

Attitude towards people with mental illness is studied in many regions of the world such as Chicago (Watson, Corrigan, \& Ottati, 2004); China (Sun, Fan, Nie, Zhang, Huang, He, \& Rosenheck, 2014); Hong Kong (China) (Todor, 2013); India (Poreddi, Thimmaiah, \& Math, 2015); Israel (Kimhi, Barak, Gutman, Melamed, Zohar, \& Barak, 1998); Saudi Arabia (Amira, 2016). Studies on attitude 
towards people with mental illness in Nigeria (Iheanacho, Marienfeld, Stefanovics, \& Rosenheck, 2014) among medical and nursing students; also among clergy (Igbinomwanhia, James, \& Omoaregba, 2013).

Previous researches show that a lack of familiarity is associated with prejudicial attitudes about mental illness (Corrigan, Green, Lundin, Kubiak, \& Penn, 2001). The present study uses police officers who come in contact with people with mental illness in the course of duty. Although there are studies on attitude towards people with mental illness in Nigeria among police (Omoaregba, James, Igbinowanhia, \& Akhiwu, 2015), the present study provides information on the influence of emotional empathy and social distance on attitude towards people with mental illness among police officers.

Based on literature review the following hypotheses were stated:

\section{Hypotheses}

Hypothesis 1: There will be significant joint prediction of emotional empathy and social distance on attitude towards people with mental illness.

Hypothesis 2: There will be sex difference in the attitude towards people with mental illness among police officers.

\section{Method}

\subsection{Research Design}

The design used for the study was a cross-sectional survey design. The study aimed at measuring independent variables which are emotional empathy and social distance while the dependent variable is attitude towards mental illness.

\subsection{Study Setting}

The study was carried out at the Police College, Ikeja. Ikeja is the capital of Lagos State in Nigeria.

\subsection{Participants}

The research population were police officers at the Police College, Ikeja, Lagos State. The study took place between October 2017 and May 2018. There were 300 participants from the Police College, Ikeja, Lagos surveyed in this study at different levels selected using purposive sampling method. The sex distribution of participants shows that $148(49.3 \%)$ of the participants were males and 152 (50.7\%) of the participants were females. The exclusion criteria are that recruits and civilians were not utilised in this study.

\section{Instruments}

Demographic section was used to obtain participant's personal information such as age and sex that was useful for the study.

The Community Attitude towards Mental Illness (CAMI) scale was used to measure participants' attitude towards mental illness. The CAMI is a 40 -item 
scale developed by Taylor and Dear (1981). The CAMI scale has four (4) sub-scales which measures Authoritarianism, Benevolence, Social restrictiveness and Community mental health ideology and each sub-scale has ten (10) items. The scale was on a 5-point Likert scale ranging from Strongly Agree (5) to Strongly Disagree (1). The scale is scored and the final total is obtained by adding all the scores of each sub-scale. Participants either exhibited a less or more sympathetic attitude towards mental illness. The author reported internal reliability of the subscales as Authoritarianism [ $\alpha .68]$, Benevolence [ $\alpha$.76] Social restrictiveness [a .80], and Community Attitude towards Mental Health Ideology [a .88].

The Multi-Dimensional Emotional Empathy Scale (MDEE) is a 30 -item scale developed by Alloway, Copello, Loesch, Soares, Watkins, Miller and Ray (2016). MDEE scale consists of items that measure the level of emotional empathy of participants on a 5 -point Likert scale ranging from $1=$ strongly disagree to 5 = strongly agree. MDEE scale consists of six (6) factor-based scales: empathic suffering; positive sharing; responsive crying; emotional attention; feeling for others and emotional contagion. Higher score on the MDEE scale indicates high level of emotional empathy while lower score on the MDEE scale indicates low level of emotional empathy. The author reported an internal reliability of [a.88].

The Social Distance Scale (SDS) was initially developed by Bogardus (1925, 1926, 1933) adopted by (Akinbobola, 2017; Wong, Smith, \& Locke, 2014). Bogardus initially applied the social distance scale to race and ethnicity however researchers Cummings and Cummings (1957) first made use of it in a mental health framework. The social distance scale used for this study was developed by Link, Cullen, Frank and Wozniak in 1987 and it consisted of seven-item on a 4-point Likert scale. The social distance scale by Link, Cullen, Frank and Wozniak (1987) was used to test how distant participants are from those with mental illness. According to Wong, Smith and Locke (2014) social distance scales are most commonly used measures of stigma especially when investigating attitudes of the general public towards mental illness. A vignette describing a case of schizophrenia was presented to participants at the beginning of the study. Social distance statements include references to someone like the man in the vignette, named Bolu. The items do not simply refer to mental illness in general however are linked to the vignette. For example, the scale contains positively worded statements such as, "Will you rent a room in your home to someone like Bolu"? Participants are hence reminded of the man in the vignette to ensure that the Social Distance Scale is measuring what it is supposed to. The responses range from definitely unwilling (0), unwilling (1), willing (2) and definitely willing (3). All seven items do appear to measure social relationships according to varying distances. The content validity according to the authors is to be acceptable because the items do cover a range of social situations including work relationships, children, neighbour, roommate, friend, and babysitter. The total score is obtained by adding up the all the scores. The author reported an internal reliability of .92 . 


\section{Procedure}

A total of 350 questionnaires were distributed to participants at their duty posts. The questionnaire comprised of 4 sections which are the demographic section and three scales namely Community Attitude towards Mental Illness (CAMI) test, Multi-Dimensional Emotional Empathy (MDEE) and Social Distance scale. The filled questionnaires were collected back and participants were thanked for their participation as well as their time. 300 (85.7\%) out of the questionnaires returned were completely. Participants were given a consent form and were asked to tick the "box" provided on the form indicating their willingness to take part in the study. They were genuinely assured of their confidentiality. Participants were then given the questionnaire comprising of the Community Attitude towards Mental Illness (CAMI) test, the Multi-Dimensional Emotional Empathy (MDEE) and the Social Distance Scale. After they had completed the study, tests were collected back and participants were thanked for their participation as well as their time. Statistical tests used for data analysis were simple percentage, t-test and regression analysis.

\section{Result}

Hypothesis 1: There will be significant joint prediction of emotional empathy and social distance on attitude towards people with mental illness.

The analysis result in Table 1 indicated that there is significant joint prediction of emotional empathy and its dimensions (suffering, positive sharing, responsive crying, emotional attention, feel for others, emotional contagion) and social distance on attitude towards people with mental illness $[\mathrm{F}(7,292)=2.85, P$ $<.01)$. Further examination from Table $1\left(\mathrm{R}^{2}=0.064\right)$ indicated that the independent variables emotional empathy and its dimensions (suffering, positive sharing, responsive crying, emotional attention, feel for others, emotional contagion) and social distance explained $6.4 \%$ variation in attitude towards people with mental illness. The hypothesis is accepted. Furthermore, it is observed from Table 2 however that only emotional empathy $(\beta=.58, \mathrm{t}=2.46, p<0.01)$ and only two of its dimensions [positive sharing $(\beta=-.52, \mathrm{t}=-3.84, P<0.01)$, responsive crying $(\beta=-.15, \mathrm{t}=-2.06, P<0.05)]$ had significant independent influence on attitude towards people with mental illness; the remaining four dimensions have no significant independent prediction on attitude towards people with mentally illness.

Table 1. Regression analysis of emotional empathy with 6 dimensions (suffering, positive sharing, responsive crying, emotional attention, feel for others, emotional contagion) and social distance on attitude towards people with mental illness.

\begin{tabular}{ccccccc}
\hline MODEL & Sums of square & df & Mean Sq. & F & $\boldsymbol{P}$ & $\mathrm{R}^{2}$ \\
\hline Regression & 1562.082 & 7 & 223.155 & & & \\
Residual & $22,824.888$ & 292 & 78.167 & 2.85 & .01 & .064 \\
Total & $24,386.970$ & 299 & & & & \\
\hline
\end{tabular}


Table 2. Multiple regression analysis of emotional empathy with 6 dimensions (suffering, positive sharing, responsive crying, emotional attention, feel for others, emotional contagion) and social distance on attitude towards people with mental illness.

\begin{tabular}{cccc}
\hline Variables & Beta & $\mathbf{t}$ & $\boldsymbol{P}$ \\
\hline Suffering & .02 & .13 & $>.05$ \\
Positive Sharing & -.52 & -3.83 & $<.01$ \\
Responsive crying & -.15 & -2.06 & $<.05$ \\
Emotional Attention & -.09 & -1.22 & $>.05$ \\
Feel for Others & -.11 & -1.19 & $>.05$ \\
Emotional Contagion & -.06 & -.92 & $>.05$ \\
Emotional Empathy & .58 & 2.50 & $<.01$ \\
SD & -.09 & -1.58 & $>.05$ \\
\hline
\end{tabular}

Table 3. Summary of analysis of independent t-test for male and female police officers attitude towards people with mental illness.

\begin{tabular}{ccccccc}
\hline Variable & $\mathbf{N}$ & $\mathbf{X}$ & SD & df & t & $\boldsymbol{P}$ \\
\hline MALE & 148 & 121.95 & 9.865 & 298 & & \\
FEMALE & 152 & 120.10 & 8.012 & & -1.78 & $<.05$ \\
\hline
\end{tabular}

Hypothesis 2: There will be sex difference in the attitude towards people with mental illness among police officers.

An independent sample t-test was carried out to determine the influence of sex on the attitude of police officers towards people with mental illness. The $\mathrm{t}$-Test scores showed that there were 148 male and 152 female police officers surveyed, while the mean $( \pm \mathrm{SD})$ of attitude scores were $121.95 \pm 9.86$ and 120.10 \pm 8.01 respectively (See Table 3 ). The significant 2 -tailed $\mathrm{P}$ value associated with this test was .000 . The $\mathrm{t}$-Test reveals a statistically significantly reliable difference between the mean of attitude scores of the male police officers and that of the female counterparts $[\mathrm{t}(298)=-1.78, p<.05]$. It can be therefore concluded that there is a significant sex difference in the attitude of police officers on people with mental illness. Further analysis showed that male police officers reported higher mean scores than their female counterparts, suggesting that male officers exhibited more positive attitude towards people with mental illness than female participants.

\section{Discussion}

The findings of hypothesis one indicated that there is significant joint prediction of emotional empathy and its dimensions (suffering, positive sharing, responsive crying, emotional attention, feel for others, emotional contagion) and social distance on attitude towards people with mental illness. These findings that emotional empathy predicted attitude towards people with mental illness corroborated (Boag \& Carnelley, 2015; Batson et al., 1997; Elizur \& Rosenheim, 1982; 
Oliver, Dillard, Bae, \& Tamul, 2012).

Empathy involves emotion and cognition and it is theorised in different ways. Foster, Elischberger and Hill (2017) suggested that an intervention approach would be very effective if empathic understanding is being encouraged. They further state that the inducing of empathy has assisted in reducing stigma projected at members of stigmatized group.

The findings of hypothesis one further revealed that social distance significantly predicted attitude towards people with mental illness substantiate previous result (Aghanwa, 2004; Reese, 2010). Social distance measures the degree of closeness that participants would be willing to take with respect to those who suffer mental illness. This finding shows that there is stereotypic stigma towards people with mental illness.

The findings of hypothesis two revealed that there is sex difference in the attitude towards people with mental illness among police officers. Male police officers have a more positive attitude towards people with mental illness than female police officers. The findings of hypothesis two did not support past researches Gonzalez, et al. (2005) and Berger et al. (2005) in which females participants have a more positive attitude towards people with mental illness. Both male and female police officers have much opportunity to come in contact with people with mental illness when performing their duty, but female police officers attitude is comparatively positive. Considering various professional groups that interact with people with mental illness in the course of duty, next to health professionals are police officers. Mental health professionals endorse negative attitudes toward those who have serious mental illness and avoid contact with such people to the extent that self-report measure of people with mental illness indicated that they have been treated as less capable and rejected by others (Reese, 2010; Jorm, Korten, Jacomb, Christensen, \& Henderson, 1999).

\section{Implication of Findings}

1) People with mental illness are stigmatized by police officers and may be treated as criminals and not as either suspects or victims before they get judged.

2) Police officers with prejudicial attitude towards mental illness are likely to stigmatize people with mental illness and hence constitute security lapses in the nation's criminal justice system.

3) There is a lack of emphatic concern by the police officers in dealing with people with mental illness; the mentally ill may withdraw to their shell.

\section{Recommendation}

There is a need for inclusion of the role of psychologist to train police officers on the knowledge of mental illness, adherence to zero tolerance for stigmatisation of people with mental illness and to give intervention to police officers on empathic altruism and concern. 


\section{Limitation of Study}

The present study made use of police officers in only one Police College out of a total of six Police Colleges in the country.

\section{Suggestion for Future Studies}

Future studies should look into attitude of the public and various professional groups towards other groups of vulnerable people that are stigmatised and the causes of stigmatisation.

\section{Conflicts of Interest}

The authors declare no conflicts of interest regarding the publication of this paper.

\section{References}

Adeosun, I., Fatiregun, O., \& Adeyemo, S. (2017). Social Distance towards People with HIV-AIDS versus Mental Illness in a Sample of Adolescent Secondary Students in Lagos Nigeria. Journal of Education, Society and Behavioural Science, 22, 1-7. https://doi.org/10.9734/JESBS/2017/36128

Aghanwa, H. S. (2004). Attitude toward and Knowledge about Mental Illness in Fiji Islands. International Journal of Social Psychiatry, 50, 361-375. https://doi.org/10.1177/0020764004050336

Akinbobola, I. O. (2017). Behavioural Intention and Perception of Ethnic Groups among National Youth Service Corp Members in Nigeria. IFE PsychologIA, 25, 1-18.

Albarracin, D., \& Shavitt, S. (2018). Attitudes and Attitude Change. Annual Review of Psychology, 69, 299-327. https://doi.org/10.1146/annurev-psych-122216-011911

Alloway, T. P., Copello, E., Loesch, M., Soares, C., Watkins, J., Miller, D., \& Ray, S. (2016). Investigating the Reliability and Validity of the Multidimentional Emotional Empathy Scale. Measurement, 90, 438-442. https://doi.org/10.1016/j.measurement.2016.05.014

Altindag, A., Yanik, M., Ucok, A., Alptekin, K., \& Ozkan, M. (2006). Effects of an Antistigma Program on Medical Students' Attitudes towards People with Schizophrenia. Psychiatry and Clinical Neurosciences, 60, 283-288. https://doi.org/10.1111/j.1440-1819.2006.01503.x

Amira A. A. (2016). Nurses Attitudes towards People with Mental Illness. International Journal of Mental Health \& Psychiatry, 2, 4.

Baez, S., Flichtentrei, D., Prats, M., Mastandueno, R., Garcia, A. M., Cetkovich, M., \& Ibanez, A. (2017). Men, Women, Who Cares? A Population Based Study on Sex Differences and Gender Roles in Empathy and Moral Cognition. PLoS ONE, 12, e0179336. https://doi.org/10.1371/journal.pone.0179336

Batson, C. D., \& Toi, M. (1982). More Evidence That Empathy Is a Source of Altruistic Motivation. Journal of Personality and Social Psychology, 43, 281-292. https://doi.org/10.1037/0022-3514.43.2.281

Batson, C. D., Dyck, J. L., Brandt, J. R., Batson, J. G., \& Powell, A. L. (1988). Five Studies Testing Two New Egoistic Alternatives to the Empathy-Altruism Hypothesis. Journal of Personality and Social Psychology, 55, $52-77$. https://doi.org/10.1037/0022-3514.55.1.52 
Batson, C. D., Polycarpou, M. P., Harmon-Jones, E., Imhoff, H. J., Mitchener, E. C., Bedner, L. L., \& Highberger, L. (1997). Empathy and Attitudes: Can Feeling for a Member of a Stigmatized Group Improve Feelings towards the Group? Journal of Personality and Social Psychology, 72, 105-118. https://doi.org/10.1037/0022-3514.72.1.105

Berger, J. M., Levant, R., McMillan, K. K., Kelleher, W., \& Sellers, A. (2005). Impact of Gender Role Conflict, Traditional Masculinity Ideology, Alexithymia, and Age on Men's Attitudes toward Psychological Help Seeking. Psychology of Men \& Masculinity, 6, 73-78. https://doi.org/10.1037/1524-9220.6.1.73

Bhugra, D., Evans-Lacko, S., \& Cutter, W. (2015). Mentally Ill, Public Attitudes towards. In J. D. Wright (Ed.), International Encyclopaedia of the Social \& Behavioural Sciences (2nd ed., pp. 228-234). Amsterdam: Elsevier. https://doi.org/10.1016/B978-0-08-097086-8.27038-4

Boag, E. M., \& Carnelley, K. B. (2015). Attachment and Prejudice: The Mediating Role of Empathy. The British Journal of Social Psychology, 55, 337-356. https://doi.org/10.1111/bjso.12132

Bogardus, E. S. (1925). Measuring Social Distances. Journal of Applied Sociology, 12, 216-226.

Bogardus, E. S. (1926). Social Distance in the City. Proceedings and Publications of the American Sociological Society, 20, 40-46.

Bogardus, E. S. (1933). A Social Distance Scale. Sociology and Social Research, 17, 265-271.

Bolton, D. (2008). What Is Mental Disorder? An Essay in Philosophy, Science, and Values (p. 6). Oxford: Oxford University Press. https://doi.org/10.1093/med/9780198565925.001.0001

Corrigan, P. W., Green, A., Lundin, R., Kubiak, M. A., \& Penn, D. L. (2001). Familiarity with and Social Distance from People Who Have Serious Mental Illness. Psychiatric Services, 52, 953-958. https://doi.org/10.1176/appi.ps.52.7.953

Cummings, E., \& Cummings, J. (1957). Are the Ranks Closed? Attitudinal Social Distance and Mental Illness. The American Journal of Psychiatry, 127, 1121-1127.

Dogra, N., Omigbodun, O., Adedokun, T., Bella, T., Ronzoni, P., \& Adesokan, A. (2012). Nigeria Secondary School Children's Knowledge of and Attitudes to Mental Health and Illness. Clinical Child Psychology and Psychiatry, 17, 336-353. https://doi.org/10.1177/1359104511410804

Eagly, A. H., \& Chaiken, S. (2005). Attitude Research in the 21st Century: The Current State of Knowledge. In D. Albarracin, B. T. Johnson, \& M. P. Zanna (Eds.), The Handbook of Attitudes. Mahwah, NJ: Erlbaum.

Eisenberg, N., \& Lennon, R. (1983). Sex Differences in Empathy and Related Capacities. Psychological Bulletin, 94, 100-131. https://doi.org/10.1037/0033-2909.94.1.100

Elizur, A., \& Rosenheim, E. (1982). Empathy and Attitudes among Medical Students: The Effects of Group Experience. Academic Medicine, 57, 675-683.

Foster, S. D., Elischberger, H. B., \& Hill, E. D. (2017). Examining the Link between Socioeconomic Status and Mental Illness Prejudice: The Roles of Knowledge about Mental Illness and Empathy. Stigma and Health, 3, 139-151.

https://doi.org/10.1037/sah0000084

Glass, J. E., Mowbray, O. P., Link, B. G., Kristjansson, S. D., \& Bucholz, K. K. (2013). Alcohol Stigma and Persistence of Alcohol and Other Psychiatric Disorders: A Modified Labelling Theory Approach. Drug and Alcohol Dependence, 133, 685-692. 
https://doi.org/10.1016/j.drugalcdep.2013.08.016

Gonzalez, J. M., Alegria, M., \& Prihoda, T. J. (2005). How Do Attitudes toward Mental Health Treatment Vary by Age, Gender, and Ethnicity/Race in Young Adults? Journal of Community Psychology, 33, 611-629. https://doi.org/10.1002/jcop.20071

Gosselin, E., Bourgault, P., \& Lavoie, S. (2016). Association between Job Strain, Mental Health and Empathy among Intensive Care Nurses. Nursing in Critical Care, 21, 137-145. https://doi.org/10.1111/nicc.12064

Hojat, M., Louis, D. Z., Maio, V., \& Gonnella, J. S. (2013). Editorial: Empathy and Health Care Quality. American Journal of Medical Quality, 28, 6-7. https://doi.org/10.1177/1062860612464731

Ifijeh, M. (2015). Nigeria: "21 Million Nigerians Have Psychiatric Disorder”. ThisDay. http://allafrica.com12/2/2015

Igbinomwanhia, N. G., James, B. O., \& Omoaregba, J. O. (2013). The Attitudes of Clergy in Benin City, Nigeria towards Persons with Mental Illness. Africa Journal of Psychiatry, 16, 196-200. https://doi.org/10.4314/ajpsy.v16i3.26

Iheanacho, T., Marienfeld, C., Stefanovics, E., \& Rosenheck, R. A. (2014). Medical and Nursing Students' Attitude towards People with Mental Illness in Nigeria: A Tale of Two Teaching Hospitals. International Psychiatry, 11, 43-45. https://doi.org/10.1192/S1749367600004380

Interpol (2016). Nigeria/Africa/Member Countries/Internet/Home-INTERPOL. https://www.interpol.int/

Jonason, P. K., \& Krause, L. (2013). The Emotional Deficits Associated with the Dark Triad Traits: Cognitive Empathy, Affective Empathy and Alexithymia. Personality and Individual Differences, 55, 532-537. https://doi.org/10.1016/j.paid.2013.04.027

Jorm, A. F., Korten, A. E., Jacomb, P. A., Christensen, H., \& Henderson, S. (1999 Attitudes towards People with a Mental Disorder: A Survey of the Australian Public and Health Professionals. Australian and New Zealand Journal of Psychiatry, 33, 77-83. https://doi.org/10.1046/j.1440-1614.1999.00513.x

Kimhi, R., Barak, Y., Gutman, J., Melamed, Y., Zohar, M., \& Barak, I. (1998) Police Attitudes toward Mental Illness and Psychiatric Patients in Israel. Journal of the American Academy of Psychiatry and the Law, 26, 625-630.

Link, B. G., Cullen, F. T., Struening, E., Patrick, E., Shrout, P. T., \& Dohrenwend, P. B. (1989) A Modified Labeling Theory Approach to Mental Disorders: An Empirical Assessment. American Sociological Review, 54, 400-423. https://doi.org/10.2307/2095613

Link, B., Cullen, F. T., Frank, J., \& Wozniak, J. (1987) The Social Rejection of Ex-Mental Patients: Understanding Why Labels Matter. American Journal of Sociology, 92, 1461-1500. https://doi.org/10.1086/228672

Marie, D., \& Miles, B. (2008). Social Distance and Perceived Dangerousness across Four Diagnostic Categories of Mental Disorder. Australian and New Zealand Journal of Psychiatry, 42, 126-133. https://doi.org/10.1080/00048670701787545

McAllister, M. (2008). Looking Below the Surface: Developing Critical Literacy Skills to Reduce the Stigma of Mental Disorders. Journal of Nursing Education, 47, 426-430. https://doi.org/10.3928/01484834-20080901-06

Nordt, C., Rossler, W., \& Lauber, C. (2006). Attitudes of Mental Health Professionals toward People with Schizophrenia and Major Depression. Schizophrenia Bulletin, 32, 709-714. https://doi.org/10.1093/schbul/sbj065

Oduguwa, A. O., Adedokun, B., \& Omigbodun, O. O. (2017). Effect of a Mental Health Training Programme on Nigerian School Pupils' Perceptions of Mental Illness. Child 
and Adolescent Psychiatry and Mental Health, 11, 19.

https://doi.org/10.1186/s13034-017-0157-4

Oliver, M. B., Dillard, J. P., Bae, K., \& Tamul, D. T. (2012). The Effect of Narrative News Format on Empathy for Stigmatized Groups. Journalism and Mass Communication Quarterly, 89, 205-224. https://doi.org/10.1177/1077699012439020

Omoaregba, J. O., James, B. O., Igbinowanhia, N. G., \& Akhiwu, W. O. (2015). The Attitudes of the Police towards Persons with Mental Illness: A Cross-Sectional Study from Benin City, Nigeria. American Journal of Applied Psychology, 3, 57-61. http://pubs.sciepub.com/ajap/3/3/2

Omori, A., Tateno, A., Ideno, T., Takahashi, H., Kawashima, Y., Takemura, K., \& Okubo, Y. (2012). Influence of Contact with Schizophrenia on Implicit Attitudes towards Schizophrenia Patients Held by Clinical Residents. BMC Psychiatry, 12, 205. https://doi.org/10.1186/1471-244X-12-205

Poreddi, V., Thimmaiah, R., \& Math, S. B. (2015). Attitudes toward People with Mental Illness among Medical Students. Journal of Neurosciences in Rural Practice, 6, 349-354. https://doi.org/10.4103/0976-3147.154564

Reese, D. D. (2010). Games to Evoke and Assess Readiness to Learn Conceptual Knowledge. In R. V. Eck (Ed.), Gaming and Cognition: Theories and Perspectives from the Learning Sciences (pp. 227-254). Hershey, PA: IGI Global.

Rusch, N., Angermeyer, M. C., \& Corrigan, P. W. (2005). Mental Illness Stigma: Concepts, Consequences and Initiatives to Reduce Stigma. European Psychiatry, 20, 529-539. https://doi.org/10.1016/j.eurpsy.2005.04.004

Sarbin, T. R., \& Mancuso, J. C. (1970). Failure of a Moral Enterprise: Attitude of the Public toward Mental Illness. Journal of Consulting and Clinical Psychology, 35, 159-173. https://doi.org/10.1037/h0030056

Shelton, M. L., \& Rogers, R. W. (1981) Fear-Arousing and Empathy-Arousing Appeals to Help: The Pathos of Persuasion. Journal of Applied Social Psychology, 11, 366-378. https://doi.org/10.1111/j.1559-1816.1981.tb00829.x

Shruti, A., Singh, S., \& Kataria, D. (2016). Knowledge, Attitude and Social Distance Practice of young Undergraduates towards Mental Illness in India: A Comparative Analysis. Asian Journal of Psychiatry, 23, 64-69. https://doi.org/10.1016/j.ajp.2016.07.012

Sotubo, J. (2015). 21 Million Nigerians Suffer from Mental Illness. http://www.pulse.ng

Sun, B., Fan, N., Nie, S., Zhang, M., Huang, X., He, H., \& Rosenheck, R. A. (2014). Attitudes towards People with Mental Illness among Psychiatrists, Psychiatric Nurses, Involved Family Members and the General Population in a Large City in Guangzhou, China. International Journal of Mental Health Systems, 8, 26. https://doi.org/10.1186/1752-4458-8-26

Todor, I. (2013). Opinions about Mental Illness. Procedia-Social and Behavioural Sciences, 82, 209-214. https://doi.org/10.1016/j.sbspro.2013.06.247

Toussaint, L., \& Webb, J. R. (2005). Gender Differences in the Relationship between Empathy and Forgiveness. The Journal of Social Psychology, 145, 673-685. https://doi.org/10.3200/SOCP.145.6.673-686

Tully, T., \& Smith, M. (2015). Officer Perception of Crisis Intervention Team Training Effectiveness. The Police Journal: Theory, Practice and Principles, 88, 51-64. https://doi.org/10.1177/0032258X15570558

Wong, D. S., Smith, S., \& Locke, C. R. (2014). Social Distancing of Depressive and Panic Disorders in an International Sample of Social Work Students. Advances in Social Work, 15, 480-494. 
Yap, M. B., Mackinnon, A., Reavley, N., \& Jorm, A. F. (2014). The Measurement Properties of Stigmatizing Attitudes towards Mental Disorders: Results from Two Community Surveys. International Journal of Methods in Psychiatric Research, 23, 49-61. https://doi.org/10.1002/mpr.1433

Yuan, Q., Abdin, E., Picco, L., Vaingankar, J. A., Shahwan, S., Jeyagurunathan, A., \& Subramaniam, M. (2016). Attitudes to Mental Illness and Its Demographic Correlates among General Population in Singapore. PLoS ONE, 11, e0167297.

https://doi.org/10.1371/journal.pone.0167297 